\title{
3
}

\section{Investing in the Future: Human and Social Service Development in Northern Australia}

\author{
Hurriyet Babacan and Narayan Gopalkrishnan
}

\section{Introduction}

Development in Northern Australia has a long history of government and policy interest with renewed political and media attention in recent years. In particular, the need for economic diversification and economic growth has become a central focus (Australian Government, 2015). There is universal agreement that strong, resilient and healthy individuals, families and community play a vital role in building ongoing prosperity, wellbeing and economic development. It has been demonstrated that long-term economic growth in regions occurs through investment in human capital development (Babacan \& Babacan, 2007; OECD, 2016; United Nations Economic and Social Commission for Asia Pacific, 2013). Lack of appropriate investment in the health and social services impedes Northern Australia's competitiveness and reinforces the persistence of human capital weaknesses, as well as increasing regional costs for the provision of social services (RAI, 2015; OECD, 2016).

Northern Australia is characterised by diverse populations living in communities that are regional, rural, remote or very remote. Northern Australia is challenged by critical factors that exacerbate aspects of spatial disadvantage. Northern Australia faces a significant range of social issues concerning the provision of, and access to, human and social services. 
These have major impacts on human development and social capital. This chapter explores the nature of disadvantage in Northern Australia and key challenges in the provision of human and social services, and argues that a 'one-size-fits-all' approach will not work given the diversity, governance, social, environmental and economic issues unique to Northern Australia communities. The chapter examines the nature of social issues and current health and human services investment in Northern Australia. It also examines service delivery models and governance frameworks and argues that there is a need to develop models that provide preventative, sustainable outcomes for communities into the future.

\section{Brief Glance at Northern Australia}

Northern Australia comprises over 1.2 million people; approximately 6 per cent of the national population (RAI, 2013). The area described as Northern Australia is located across three jurisdictions-Queensland, Western Australia (WA) and the Northern Territory (NT). It covers 74 local government areas (LGAs) — eight in WA, 16 in the NT and 50 in Queensland. There is a significant level of variability within and between regions in Northern Australia.

Aboriginal and Torres Strait Islander peoples have a strong presence and interest in Northern Australia. A quarter of the people who usually reside in Northern Australia are Indigenous (Stoeckl, 2010, p. 106). For example, 67,000 Aboriginal people represent 32 per cent of the total NT population (Manderson, 2008). The Indigenous population is expected to continue to grow at a faster rate than the non-Indigenous population (1.97 per cent per annum compared to 1.78 per cent) (Carson et al., 2009). Stoeckl (2010, p. 106) concludes that 'Indigenous people are not only an important and numerically significant part of this region's current population, but they will become even more important in the years ahead'.

Northern Australia can be considered regional, rural or remote. While there is much debate about what these terms mean, the rural, remote and metropolitan areas (RRMA) classification developed by the Australian Government specifies them as follows:

- 'regional' refers to non-urban centres with a population over 25,000 and with relatively good access to services

- 'rural' refers to non-urban localities of under 25,000 with reduced accessibility 
- 'remote' communities are those of fewer than 5,000 people with very restricted accessibility

- 'metropolitan' has a population equal to or greater than 100,000 (Roufeil \& Battye, 2008, p. 3).

Most of Northern Australia fits in the definition of regional, rural and remote, with only five towns having a population larger than 70,000, 13 comprising between 15,000 and 70,000 people, and 55 with populations of less than 15,000 in 2011 (RAI, 2013, p. 31). A range of social issues concerning the provision of, and access to, social services can be linked back to spatial location, as will be explored in the next section.

While there is a renewed focus on Northern Australia, disparities and inequities exist in a number of ways between Northern Australia and the rest of Australia, between Northern Australia locations and across population groups. The key priorities of the Regional Development Australia (RDA) Committees reflect the issues facing Northern Australia. The top issue identified by RDA was infrastructure, including basic infrastructure such as power, water and waste management. Diversification of the economic base, information and communication technologies and access to affordable housing, basic health services and education are other important areas of focus.

The Regional Australia Institute (RAI) (2013, p. 11), the think tank for regional development established by the Australian Government, states that 'regional development in northern Australia requires a range of approaches that address both the variability and the disparity; between the north and the rest of Australia, between and within regions, and between population groups'.

\section{Spatial Dimensions of Disadvantage in Northern Australia}

Northern Australia comprises 2,773,000 km², comprising 36 per cent of the land mass of Australia. The connection between disadvantage, demography and geography are well established (AIHW, 2014a, 2014b; Cheers \& Taylor, 2001; Chenoweth \& Stehlik, 2001). The factors that exacerbate aspects of rural disadvantage have been identified as financial strain, family and community relationships, out-migration from rural areas, changing gender roles, lack of support services and social isolation 
(AIHW, 2014a, 2014b; Hall \& Scheltens, 2005). The AIHW (2017a, 2017b) has identified that life expectancy, income and education levels are lower for people in regional, remote and rural areas.

Cheers and Taylor (2001, p. 207) argue that people in rural areas are disadvantaged in comparison to urban people on most of the social and economic indicators including life chances, income levels, poverty, unemployment, living costs, housing quality, health status, education, and a range of social problems, and in gaining access to health, welfare, community, personal support, and essential services'. The AIHW (2014a, p. 4) points out that a lack of access to services in areas with geographically dispersed populations may affect the overall health and wellbeing of the populations living in those areas, especially in remote and very remote areas.

The persistence of locational inequality in rural/regional Australia is attributed to multiple factors including structural changes to the Australian economy, which 'through processes of circular cumulative causation' embed spatial disadvantage (Saunders \& Wong, 2014, p. 132). In a national study of exclusion and deprivation, Saunders and Wong (2014) demonstrated that differences within and between where people live make a difference to wellbeing. They demonstrated that people living in rural and country towns (small and large) face deprivation in relation to economic status, wellbeing, material deprivation, social exclusion, disengagement and service availability. They posit that disadvantage can become entrenched and reinforce itself and be transmitted across generations.

There is a long list of social issues affecting people across Northern Australia, including mental health (Fragar et al., 2007) and acquired brain injury (Stephens et al., 2014), domestic violence (Wendt \& Hornosty, 2010), aged care (Winterton \& Warburton, 2011), disabilities (Massey et al., 2013) and poorer health, including lower life expectancy (AIHW, 2014a). Financial strain, high unemployment, low educational attainment, out-migration from rural areas, changing gender roles, domestic and family violence, suicide, social isolation, discrimination, marginalisation and deprivation are terms used to characterise the link between rural disadvantage and wellbeing (Hall \& Scheltens, 2005). Significant to severe disadvantage persists in Indigenous and Torres Strait Islander communities across the north in key social areas such as life expectancy, education, income, labour market participation and health (Babacan, 2014). 
Spatial disadvantage in Northern Australia is evident from the following data. The Australian Bureau of Statistics (ABS) calculates the SocioEconomic Indexes for Area (SEIFA). The index is derived from attributes that reflect disadvantage such as low income, low educational attainment, high unemployment and jobs in relatively unskilled occupations-the lower the SEIFA score, the higher the disadvantage. Based on 2016 Census data (ABS, 2016), the SEIFA index in Northern Australia demonstrates disadvantage in a significant number of LGAs (see Table 3.1). It should be noted that the average Australian SEIFA score is 1,000 . The overall SEIFA score of Northern Australia is 970, based on 2011 Census data (Public Health Information Development Unit, 2014).

Table 3.1: Selected Socio-Economic Indexes for Areas (SEIFA) scores for Northern Australia.

\begin{tabular}{|c|c|c|c|c|c|}
\hline State & LGA & $\begin{array}{l}\text { SEIFA } \\
\text { score }\end{array}$ & State & LGA & $\begin{array}{l}\text { SEIFA } \\
\text { score }\end{array}$ \\
\hline \multirow[t]{17}{*}{ Qld } & Aurukun & 641 & \multirow[t]{5}{*}{ WA } & Broome & 979 \\
\hline & Burke & 915 & & Derby-West Kimberly & 796 \\
\hline & Cairns & 971 & & Halls Creek & 718 \\
\hline & Carpentaria & 874 & & Wyndham-East Kimberly & 941 \\
\hline & Charters Towers & 914 & & & \\
\hline & Cloncurry & 946 & \multirow[t]{12}{*}{ NT } & Alice Springs & 1015 \\
\hline & Etheridge & 929 & & Central Desert & 697 \\
\hline & Hopevale & 699 & & Darwin & 1057 \\
\hline & Kowanyama & 676 & & East Arnhem & 562 \\
\hline & Mackay & 966 & & Katherine & 990 \\
\hline & Mareeba & 936 & & Palmerston & 1033 \\
\hline & Mt Isa & 972 & & Roper Gulf & 709 \\
\hline & Townsville & 976 & & Victoria Daly & 753 \\
\hline & Tablelands & 932 & & West Arnhem & 735 \\
\hline & Torres Strait Islands & 759 & & & \\
\hline & Winton & 941 & & & \\
\hline & Yarrabah & 651 & & & \\
\hline
\end{tabular}

Note: LGA = local government area, QId = Queensland, WA = Western Australia, NT = Northern Territory.

Source: ABS (2016) SEIFA Indexes Data. 
Table 3.1 clearly demonstrates socioeconomic disadvantage across much of Northern Australia. The disadvantage is also evident in large regional cities such as Cairns and in more remote areas. Areas with high Indigenous populations have the lowest SEIFA scores in the nation.

The key indicators of the disadvantage is outlined by Catholic Social Services Australia (CSSA) (2014). They argue that there is greater government and welfare dependence in Northern Australia with indications such as lower median weekly income (i.e. 75 per cent of the Statistical Local Areas in Australia with a lower median individual weekly income), increased drug and alcohol issues, limited housing stock and poor infrastructure. The high cost of living is a critical issue in Northern Australia, particularly in food, housing and transport, which compounds the disadvantage of the people on low incomes (CSSA, 2014, pp. 6-7). The RAI identifies that Northern Australia is well below the national average for six of the nine indicators of the competitiveness index. They point out that while Northern Australia has a very high national average competitiveness in the economic fundamentals, it is hampered by significantly below average competitiveness in human capital and infrastructure and essential services (RAI, 2013, p. 21). The areas of human capital they identified include early childhood performance, school performance (primary and secondary) and English language proficiency. The RAI (2013, p. 26) also identifies barriers to accessing health services as a significant issue. The national Patient Experience Survey 2017-2018 (ABS, 2017) verifies this. The survey identified that 21 per cent of people in outer regional/remote/ very remote areas waited longer than they felt was acceptable to get an appointment with a general practitioner (GP) (compared to 18 per cent in major cities), and 33 per cent of people reported they could not see their preferred GP on one or more occasions (compared to 25 per cent in major cities). There are flow-on impacts of lack of access to services. For example, in Northern Queensland there is a high incidence of presenting to emergency departments of hospitals due to lack of access to primary health care providers; approximately 46 per cent of the population presented to emergency departments in 2015, compared to 25 per cent nationally (Northern Queensland Primary Health Network, 2017). The GP rate is calculated as number of GPs per 100,000 people. In Northern Queensland, the average GP rate is 86 , compared to the national average of 110.6 and 105.5 in Queensland (Northern Queensland Primary Health Network, 2017, p. 30). Preventable hospitalisations for Northern Australia were higher than for North Queensland, with 2,981 people per 100,000 . For the NT, this was 4,891 people, compared to 
the national figure of 2,430 (National Health Priority Areas, 2014). The number of people who could not access professional services for emotional health and wellbeing was approximately 19 per cent in remote areas, compared to 6.2 per cent in major cities (AIHW, 2017b).

Indigenous disadvantage continues in Northern Australia in key social areas such as life expectancy, education, income, labour market participation and health. For example, the gap in life expectancy between Indigenous and non-Indigenous people was 10.6 years for males and 9.5 years for females (Australian Government, 2014). Literacy levels are also poor. Between 2008 and 2013, the proportion of Indigenous students at or above the National Minimum Standards (NMS) in reading and numeracy has shown improvement in only two out of eight indicators. Only 31 per cent of Indigenous students in remote areas reached NMS in Year 9 in 2013. Only 38.5 per cent of Indigenous people aged 20-24 years in remote areas had completed Year 12 in 2012. The proportion of Indigenous people aged 15-64 who were employed in 2012 was 47.5 per cent, compared to 75.6 per cent for non-Indigenous people (Australian Government, 2014).

A number of government responses have been initiated over the last decade. Some of these have been highly contentious, particularly relating to the NT Intervention. A number of initiatives were delivered to address key issues and disadvantage including Closing the Gap and the National Partnership Agreement on Remote Service Delivery. The evaluation of Closing the Gap and the National Agreement noted some improvements in addressing Indigenous disadvantage and access to services, but concluded:

there had been no improvement in Indigenous school attendance over five years. The record of progress against other targets has also been disappointing. There has been no progress on the employment target and while Indigenous life expectancy has improved, the pace of change is far too slow to close the gap by 2031 (Australian Government, 2014, pp. 3-4).

A review of Closing the Gap, a decade after its implementation, concluded that the progress on this major initiative 'has to date only been partially and incoherently implemented' and that 'mortality and life expectancy gaps are actually widening' in those localities due to improved life expectancy of non-Indigenous populations (Holland, 2018, p. 4). The government has called for a refreshed approach to Closing the Gap, as 'governments have not been able to make real in-roads into closing the gap in health equality and life expectancy for Australia's First Peoples' (Holland, 2018, p. 8). 
This section has demonstrated the nature of social disadvantage and marginalisation in Northern Australia. The issues are complex and multidimensional. While Northern Australia is seen as having economic potential, there are significant challenges in relation to developing social and human capital.

\section{Investment in Human and Community Services Sector}

Human service delivery agencies fall into three categories: communitybased (also referred to as not-for-profit or third-sector) agencies, government agencies and for-profit agencies (mainly private sector). Health and human service delivery in rural and remote areas tends to be provided by a range of providers including the three tiers of government or community service organisations (which are often publicly funded) and the private sector. For example, in the area of residential aged care, for-profit providers constitute 40 per cent of services across Australia. However, only 4.1 per cent of services are located outside of major cities and inner regional locations. Conversely, 91 per cent of all services in rural or remote areas are operated by state or federal government agencies or community-based providers (Baldwin et al., 2013, p. 8). There is a gap in the evidence about the nature of this sector in Northern Australia. It is known that there are large charitable agencies such as CSSA across Northern Australia, as well as Indigenous health agencies, government agencies and a network of smaller community organisations.

In 2015-16, total government welfare expenditure in Australia was estimated at A $\$ 157$ billion (AIHW, 2017c)—cash payments for specific populations (not including unemployment benefits) accounted for 66.8 per cent, welfare services 26.9 per cent and unemployment benefits 6.3 per cent. In this same period, the total recurrent expenditure on health was $\mathrm{A} \$ 160.2$ billion. It is worth noting that more than half (55.5 per cent) was spent in New South Wales and Victoria. Growth rates in health expenditures from 2010-11 to 2015-16 were 3.1 per cent in NSW, 3.0 per cent in Victoria, 4.1 per cent in Queensland, 4.3 per cent in Western Australia, 2.1 per cent in South Australia, 2.3 per cent in Tasmania and 1.8 per cent in the NT (AIHW, 2017b). In comparison with other developed nations, Australia ranks lower in welfare expenditure rankings. Australia's total social expenditure was estimated at 19.1 per cent of gross 
domestic product (GDP) in 2016 (OECD, 2018). Spending on welfare services in $2015-16$ was $\mathrm{A} \$ 42.3$ billion for family and child welfare services, aged services, disability services and other services (AIHW, 2017a). The average amount spent by governments on welfare services per Australian resident in 2015-16 was $A \$ 1,763$, up from $A \$ 1,512$ in 2006-07 and A \$1,667 in 2014-15 (AIHW, 2017a).

Examination of past data from 1999-2007 reveals chronic underinvestment in welfare in the states and territories that comprise Northern Australia. For example, the AIHW concludes that funding of recurrent expenditure on welfare services by all state and territory governments averaged $A \$ 421$ per person in 2005-06. States with the lowest average government funding per capita were Queensland (A\$358) and Western Australia (A \$361) (AIHW, 2007). This means that the states that constitute Northern Australia are playing catch-up. Rural and regional service providers are disproportionately impacted by curtailment in public expenditure and cutbacks in location-specific public services (e.g. centralisation of services to a regional area) (Steiner \& Teasdale, 2017; Babacan, 2013).

The data for Northern Australia is difficult to ascertain due to crossjurisdictional data collection. Additionally, the AIHW (2013, p. 399) notes that there is currently no dedicated routine monitoring of total welfare expenditure, comprising government and non-government spending, in Australia'. While aggregated data exists for government expenditure, there is little disaggregated data based on locality, region and issues addressed. Thus, an accurate assessment of investment in social and community services is currently not possible in Northern Australia.

The real costs of meeting the needs in rural, remote and very remote settings continue to be inadequately factored into current funding allocations (First Peoples Disability Network, 2013; Massey et al., 2013). A number of factors influence welfare spending including population growth, the cost of providing services and rates of service use, and capacity to pay privately. The capacity to pay privately in Northern Australia is limited (CSSA, 2014) and reflected by the small private sector human service delivery. The reason why publicly funded welfare services are provided is given by government as improving 'the lives of Australians by creating opportunities for economic and social participation by individuals, families and communities' (Department of Families, Housing, Community Services and Indigenous Affairs, 2011, p. 13) and increasing national prosperity through improvements to productivity, participation and 
social inclusion' (DEEWR, 2011). There is a recognition by the Australian Government that investing in welfare yields socioeconomic returns to society (NEF Consulting, 2010). The social return on investment evidence undertaken in international and community development fields confirms this. For example, in the United Kingdom it was found that $£ 1$ invested in local area community development yielded a return valued at $£ 15$, a social return investment ratio of 2.16:1 (NEF Consulting, 2010, p. 4). On a macro scale, there is evidence around the connection between increased public spending on human capital and improved prosperity. For example, Lamartina and Zaghini (2008), in an analysis of 23 high-income countries from 1970-2006, confirmed a positive correlation between public spending and per capita rise in GDP. It is also well established that when support systems fail the result is severe personal and systemic disempowerment (First Peoples Disability Network, 2013).

In recognising the development and preventative role of social and human services sector in Northern Australia, the RAI argues that both sectors play a vital role in the early detection and treatment of preventable health conditions. They argue that lack of appropriate investment in the sector impedes Northern Australia's competitiveness, reinforces the persistence of human capital weaknesses over time and increases regional costs for the provision of social services (RAI, 2013). Similarly, the Mineral Council of Australia, in its submission to a Parliamentary Inquiry, pointed out the need for investment in community and community infrastructure in Northern Australia:

Research suggests that communities that do not have sufficient infrastructure, social amenity and economic diversity will not attract new residents and this will in turn constrain the industry's recruitment capacity (House of Representatives Standing Committee on Regional Affairs, 2013, n.p.).

The complexity of government investment in Northern Australia is well demonstrated by the lack of progress in Closing the Gap. Holland (2018, p. 8) highlights the issues accurately:

over the decade since 2008, Aboriginal and Torres Strait Islander affairs have experienced discontinuity and uncertainty. Regular changes to the administration and quantum of funding, shifting policy approaches and arrangements within, between and from government, cuts to services, and a revolving door of Prime Ministers, Indigenous Affairs Minister and senior bureaucrats have all but halted the steady progress hoped for by First Peoples. 
Additionally, 'the introduction of new competitive tendering process for services to apply for funding grants was introduced, leading upheaval and led to uncertainty, lost continuity, and eroded engagement between Aboriginal and Torres Strait Islander organisations and government' (Holland, 2018, p. 8). Moreover, the level of funding was not commensurate with the complex needs and issues.

Recent studies have focused on social capital and community resilience. 'Resilience is the capacity for complex systems to survive, adapt, evolve and grow in the face of turbulent change' (van Opstal, 2007, p. 11). There is a positive and strong correlation between growth of human services and progressive change in communities. Winterton and Warburton (2011) demonstrated the connection between resilience and disadvantage for older adults living in rural areas. Chenoweth and Stehlik (2001) demonstrated in Queensland rural communities that human services were contributing to new forms of community resiliency. The authors cited examples from age and disability sectors, suicide prevention and mental health and financial counselling for drought-stricken communities. They argued that the potential for resiliency rests in partnerships and proactive planning at the local level. Other recent examples of building community resilience come from local government. For example, Dollery, Wallis and Akimov (2010) argue that local government service delivery scope and outreach was much broader in remote NT shires than for the city/town councils and other remote councils, covering many areas of community support. There is a strong imperative for strong communities given the challenges that face Northern Australia such as climate change, boom-bust economic cycles and significant disadvantage. Concepts of community and resilience have been associated with communities 'bouncing back', transforming' and being 'adaptive' (Kirmayer et al., 2009; Gow \& Paton, 2008).

\section{Sustainable Rural and Remote Human Service Delivery}

The delivery of human services in rural, remote and regional areas differs for a range of reasons. Distance impacts on service costs, and the productive time of community or social workers may be limited due to lack of allied supports and staff exhaustion due to travel commitments (Roufeil \& Battye, 2008). CSSA (2014) argues that it costs much more to provide a service in Northern Australia than in other parts of Australia, 
a fact not often recognised in funding models. Other factors identified as a source of impost include community pressure on the few human service professionals or service delivery agencies to be 'all things to all people' in the absence of an adequate range of health and welfare services; the long time required to foster community acceptance; challenge of managing confidentiality in small communities; limited access to other support professionals, especially specialists; difficulty in recruiting and retaining staff; limited ability of communities to pay for services; and a general reluctance to seek help when needed (Roufeil \& Battye, 2008; Judd et al., 2006).

These issues have been echoed in meetings held by one of the authors of this chapter across Northern Australia from 2010-13. An extensive consultation was undertaken in 2011, involving service providers in Far North Queensland comprising government and non-government agencies addressing issues relating to health, migrant and refugee community issues, domestic violence, mental health, substance abuse, child protection, women, Indigenous community issues, disability, ageing, housing and homelessness, poverty and community development. A number of key issues were identified including:

- Lack of resources and lack of appropriate service delivery. It was identified that, relative to need, funding did not take into account 'real service delivery costs' in rural and remote areas in Far North Queensland.

- Ad hoc planning and lack of coordination and integration, particularly across different tiers of government and service agencies. There were major gaps or duplication in services in specific locations. Nonprofit service agencies competed with the processes of tendering for funding in a competitive environment, which acted as a major barrier for collaboration across service agencies. Many participants in the consultations felt this resulted in loss of effectiveness as a sector to speak and act in a unified manner. Others voiced concern about the inability to be proactive around community needs and limitations on responsiveness due to a culture of short-term competitive funding processes in the face of chronic social problems. They also emphasised the need for preventative and outcomes-based approaches to human service planning and delivery, rather than the current reactive and crisis-based approaches. 
- Models of service delivery focused on addressing crisis intervention, rather than developing community capital and resiliency. This led to difficulties at times of crisis and major economic challenges such as climatic challenges and economic shocks.

- Difficulty of influencing policy and decision-makers who were long way away in Canberra or Brisbane. Many decision-makers had not visited Far North Queensland and did not have appropriate awareness of the issues in Far North Queensland. Community voices were inadequately represented due to a range of factors including distance, access to decision-makers and capability to translate Far North Queensland human service issues in relevant ways to policymakers. Many professional staff were identified as not having enough time to do the higher-order thinking and planning to be proactive as they were stretched responding to current demands.

- Workforce issues including difficulties of recruiting and retaining appropriately qualified workforce, loss of experienced personnel due to lack of funding and job security, and lack of career and personal development opportunities. Major concern was expressed relating to maintaining long-term service delivery viability with the 'churn over' of services and staff being commonplace. As a result, the human services sector was seen as variable in strength and coverage, often varying with funding opportunities, rather than addressing needs in any systematic manner (Babacan, 2011, 2014).

An analysis of the human services sector in Northern Australia requires an analysis of human service delivery models. As can be seen from the above list, major challenges exist across Northern Australia to achieve sustainable and functional service delivery models. Eversole (2017, p. 307) states that in the context of policy and political approaches, Australian regions are 'regularly defined through a deficit lens, and one which systematically overlooks the distinctive attributes of individual regions'. The author argues that resource management conflicts and social equity issues are regularly experienced 'in place' in regions, yet they are governed from afar by decision-makers with limited knowledge of the on-the-ground dynamics of particular regions (Eversole, 2017, p. 314).

Battye (2007, p. 5) defines a dysfunctional service model as one that does not support or enable professionals to provide care to individuals and communities on a sustainable basis. Identifying and implementing functional models of service in regional, rural and remote areas is 
not easy. Lessons learnt from Europe and OECD countries identify the need for broader approaches to human development (OECD, 2016). Policymaking is evolving and increasingly recognising social disadvantage, equity and environmental issues along with economic and imperatives for growth. There is emerging engagement with questions of sustainable regional development, recognising the interconnectivity between the economic with equity, community development, human and social capital, ecosystems, resilient institutions and strong cultures (Eversole, 2017; Babacan, 2017). The new policy lexicon demonstrates a change in focus to policy focusing on smart (linked with knowledge and innovation), sustainable (green, environmentally sound and climate change mitigation) and inclusive (equity, employment and cohesive) (Naldi et al., 2015).

Current practice in Northern Australia is mixed in service quality and sustainability, although there are no comprehensive studies available. In the absence of data, it is useful to apply a typology provided by Wakerman et al. (2008) from their study on rural and remote public health service delivery (see Figure 3.1).

\begin{tabular}{l} 
Discrete \\
Services \\
-Walk-in, walk- \\
out \\
-Specific \\
services \\
-Based in \\
specific \\
location \\
\hline
\end{tabular}
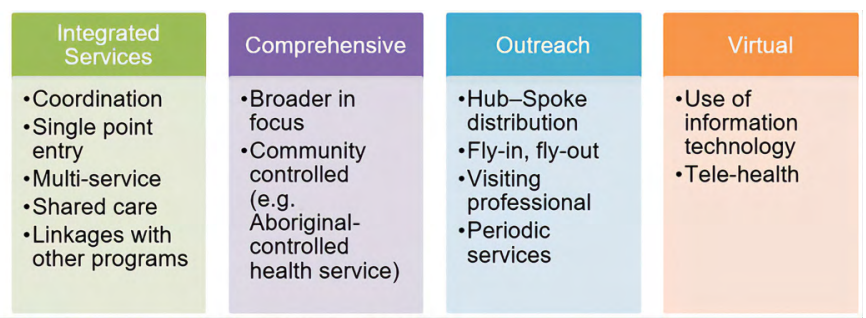

Figure 3.1: Typology for service delivery in rural and remote regions.

Source: Wakerman et al. (2008).

Each of these models has different features and advantages and disadvantages of which the scope of this chapter does not permit discussion. The authors identify essential elements of sustainable services and outline a number of enablers crucial in the provision of sustainable and accessible services. There are a number of environmental enablers, which include supportive policy that ensures sustained service funding, coordination of policy and funding, and an appropriate level of community readiness for involvement in planning and implementation of the service activity. At the service level, a number of requirements are necessary including the right number and mix of staff; adequate funding; strong governance, management and leadership; coordination and continuity of service with other agencies; 
appropriate infrastructure; and, importantly, adequate information and communication technology. It is important to note that these factors are all inter-related.

The pressure on the health and human services sector continues to build as neoliberal approaches set a trend in which the state continues incrementally to withdraw support for traditional social service areas, accompanied by market-based models of funding such as outsourcing and contracting (Gopalkrishnan, 2007). New models of financial sustainability of social services are emerging such as social entrepreneurship-enterprises for a social purpose, of which the primary objectives are social and the profit or surplus generated by business activities is reinvested into these objectives (Steiner \& Teasdale, 2017, p. 2). Research on social entrepreneurship in Northern Australia is scant and their contribution to rural development is not recognised. Unlike other parts of the world, social entrepreneurship is not recognised in policy frameworks and business development and capacity-building support is not provided by government trade and business departments. Experiences from overseas suggests that social entrepreneurship may be one of a diversity of options for Northern Australia, enabling multi-stakeholder, cross-industry and multi-level governance collaboration for sustainable outcomes (Steiner \& Teasdale, 2017; Defourny \& Nyssens, 2013) and for mobilising ideas, resources and support from external sources to benefit rural regions (Richter, 2017).

Sustainability issues need urgent attention as regional, remote and rural services are under enormous pressure and unable to meet the demands of the communities they serve (Baldwin et al., 2013; Alston \& Kent, 2004). Services in Northern Australia face problems of accessibility, availability, relevance and acceptability, especially in the more remote areas (Limerick et al., 2012; Moran et al., 2009). Regional service centres attempt to cater for more remote surrounding areas without appropriate resources. CSSA (2014, p. 5), one of the major non-profit social service agencies in Northern Australia, argues that 'a "one size fits all" approach will not work for Northern Australia given the diversity, governance, social, environmental and economic issues'.

Identifying effective and sustainable models in Northern Australia is severely constrained by a lack of evidence about 'what works best'. While there is now a growing body of evidence about the needs of communities in Northern Australia, we have a scant research base about appropriate models of services and how to respond effectively to diverse community needs. 


\section{Workforce Issues}

The health and human services industry is one of the fastest growing industries, with trend forecasting by the Department of Jobs and Small Business (2018) identifying it as the largest employment increase in Australia (14.9 per cent) over the next five years. Currently, it comprises approximately 9 per cent of GDP and provides over 10 per cent of total employment in Australia. In Far North Queensland, in 2019-20, this sector provided 19,195 jobs-14.1 per cent of the total workforce-followed by retail; accommodation and food services $(9.7 \%)$; construction $(9.4 \%)$ and agriculture, fishing and forestry (7.1\%) (Economy Id, 2021). In NT in 2021, largest industries by employment share are public administration and safety (17.4\%), health and social services (17.3\%), education and training (10\%) and retail (8.9\%) (Department of Industry, Tourism and Trade, 2021). The not-for-profit sector makes up just over 8.5 per cent of GDP, provides employment to about 10 per cent of the workforce and has nearly 3 million volunteers contributing an additional $\mathrm{A} \$ 14.6$ billion in unpaid work. It is the second-largest employing industry after health care and social assistance, and has more people than the construction (9.2\%), professional, scientific and technical services (8.6\%) and manufacturing (7.2\%) industries (Social Ventures Australia and the Centre for Social Impact, 2020, p. 3). This sector is largely dependent on public funding, although private sector models are increasingly emerging. The sector has grown immensely in the context of significant increase in needs due to an ageing population, rise in chronic disease, increased longevity, increased mental health prevalence and a range of social issues (e.g. domestic violence, homelessness and unemployment). There are major service gaps and increased unmet needs with limitations of public expenditure resulting in targeted service delivery.

The community services workforce comprises people in paid employment who provide community services such as personal and social support, child care and corrective services (AIHW, 2013). This is complemented by volunteers, family members and informal carers. In 2011, there were more than 755,000 workers in community services occupations in Australiaan increase of 24 per cent since 2006 (AIHW, 2013, p. 25). Workers in community services occupations were more likely to be female (87 per cent), employed part-time (57 per cent), older and generally earning less than the average Australian worker (AIHW, 2013, p. 25). The relative ratios of community services staff per population in geographical areas vary greatly for different occupations. Table 3.2 provides a brief analysis of the people employed by community services occupations by remoteness in 2013 . 
Table 3.2: People employed by community services occupations by remoteness (workers per 100,000 population) in 2013.

\begin{tabular}{|l|c|c|c|c|c|}
\hline Occupation & $\begin{array}{c}\text { Major } \\
\text { cities }\end{array}$ & $\begin{array}{c}\text { Inner } \\
\text { regional }\end{array}$ & $\begin{array}{c}\text { Outer } \\
\text { regional }\end{array}$ & $\begin{array}{c}\text { Remote/ } \\
\text { Very remote }\end{array}$ & Australia \\
\hline Registered nurses & 925.9 & 978.0 & 876.1 & 676.2 & 926.9 \\
\hline Counsellors & 75.2 & 68.5 & 68.9 & 68.4 & 73.2 \\
\hline Psychologists & 96.2 & 61.5 & 46.2 & 25.8 & 104.2 \\
\hline Child care workers & 503.8 & 436.4 & 448.6 & 387.7 & 483.5 \\
\hline $\begin{array}{l}\text { Age and disabled care } \\
\text { workers }\end{array}$ & 444.8 & 610.5 & 556.7 & 326.1 & 484.7 \\
\hline $\begin{array}{l}\text { Nursing support and } \\
\text { personal care workers }\end{array}$ & 315.6 & 325.6 & 321.8 & 204.3 & 315.8 \\
\hline
\end{tabular}

Source: AlHW (2013, p. 369).

The shortage of human and community services and health professionals in rural areas is well documented (Davies et al., 2009; Lonne \& Cheers, 2004; Roufeil \& Battye, 2008), although the Community Services and Health Industry Skills Council (2014) argues that there is a need for relevant and high-quality training and workforce data. They argue that appropriate planning in the sector is challenging without appropriate evidence, particularly in the context of a fast-changing policy and funding domain. The environmental scan conducted by the Community Services and Health Industry Skills Council (2014) identified shortages in aged care, child care, child protection, mental health, counselling, social workers, nurses and disability workers. The quantum of managers and senior staff in leadership roles in community services and the health sector was also identified as limited (AIHW, 2013). As can be seen from Table 3.2, the shortage of an appropriate community services workforce across different occupations increases with greater remoteness (AIHW, 2013). For example, early childhood teachers numbered 852 per 10,000 population in major cities, compared to 680 and 738 for outer regional and remote areas; nurses numbered 926 for major cities, compared to 876 and 676 for outer regional and remote areas; counsellors numbered 752 in major cities, compared to 689 and 684 in outer regional and remote areas; social workers numbered 806 in major cities, compared to 625 and 490 in outer regional and remote areas; and so on across the different occupational categories (AIHW, 2013, p. 17). 
Babacan (2011) identified challenges in recruiting and retaining an appropriate community services workforce across Northern Australia, including systemic issues such as the difficulty of attracting appropriately qualified staff, problems with retaining staff in the face of short-term funding cycles and job insecurity, difficulty of career progression, burnout and stress and lack of opportunity for professional development. These findings are echoed by others. For example, Roufeil and Battye (2008, p. 8) suggest three key areas contributing to workforce shortages: professional issues (e.g. job dissatisfaction, overload/burnout, professional isolation, lack of support and training, burden of rural travel, inadequate orientation to rural/Indigenous practice, lack of adequate remuneration and inflexible award conditions), personal factors (e.g. housing, partner employment issues and access to quality child care/education) and community factors (e.g. establishment of social networks and local facilities). Similarly, Davies et al. (2009, p. xv) found that barriers to attracting staff included negative perceptions of rural employment and lifestyle opportunities; limited health, education facilities and services; lower wages and cost of living considerations; and cost, availability and quality of housing.

The difficulty of staff development in Northern Australia has been a long-term issue. For example, Trinidad (2001) highlighted the need to invest more in the ongoing professional development of staff, building on their knowledge, skills and qualities. He stated that 'the temptation for cash-strapped agencies like ours is to put that responsibility solely on the shoulders of the individual staff member' (Trinidad, 2001, p. 12). Suggested strategies for retaining staff were competitive employment packages, improving opportunities for structured career advancement pathways, generating activities and networks to overcome issues of social isolation, providing improved access to health and education facilities, and addressing limited housing options. Collaborative regional approaches were recommended to address workforce shortages as many small employers are unable to remediate key problems such as housing.

\section{Governance Challenges}

Governance is a complex term that encompasses the way decisions are made to achieve a public good. Dale $(2013$, p. 5$)$ reminds us to a take a wide view of governance and defines it as 'how the overall system of decision-making works to deliver social, economic and environmental outcomes for our 
society'. Governance arrangements in Northern Australia are critical as the urgency of social, economic and environmental challenges have been characterised as being on the 'knife's edge' (Dale, 2013, p. 10). The RAI (2013, p. 76) identifies the central role that government (local, state and federal) plays in the economy and society of Northern Australia and posits that the effectiveness of government policies across a range of economic and social issues are central to facilitating change in Northern Australia. Regions in Northern Australia are experiencing ongoing economic and social transformation and face multifaceted change processes in a complex environment in which global and local forces intertwine. Public policies developed by the three tiers of government have formed incrementally over decades and are fragmented, confused and lacking in coherence at times (Altman \& Russell, 2012; Walker et al., 2012).

The efficacy and legitimacy of governance in Northern Australia has been the subject of discussion (Dale, 2013; Altman \& Russell, 2012). Walker et al. (2012, pp. 39-53) outline six dysfunctions of governance in remote areas, drawing on three case studies in Northern Australia:

1. Government withdrawal, across the three tiers of government, from direct service delivery and outsourcing to third parties with the expectation that the market will deliver social policy outcomes. The increase in executive power of public servants has resulted in greater focus on accountability and audit. Additionally, the power to define social problems and priorities is centralised in public authorities; however, the resolution is pushed back to local communities and individuals.

2. Organisational arrangements that are not 'fit for purpose' and, hence, the inability to meet the needs of the communities. The variable success of organisations to engage with government is a source of frustration and deficiency of the client groups. Many of the participatory and representational processes of communities, particularly Indigenous communities, are challenged by structural change such as the abolition of bodies such as Aboriginal and Torres Strait Islander Commission.

3. Adisconnect between policy and practice, with an overreaching of policy into wider domains of life and underreaching of the administrative aspects of delivery, with less resources and administrative capacity. The reason for the overreach is due to policymakers not being attuned to local realities, representational barriers, diversity, communication and the inability to apply local knowledge due to reliance on outside 
staff. The result is a greater reliance by leaders in rhetoric and grand claims of strategy to address particular issues, and in so doing gain legitimacy.

4. Inability to balance general interests of society with specific or parochial needs where there are major differences across specific issues/ needs due to differences in communities, welfare patterns, ethnicity and race markers. Applying a global standard over such diversity repudiates the various efforts by different actors.

5. Policy turbulence and instability, particularly in regard to how responsibilities are assigned up and down and across the system of government and between government, the community and the private sector. Programs come and go and various strategic plans are announced and imposed in the process by local, regional, state and federal governments. The result is the loss of accountability between government and citizens and loss of trust and build-up of animosity.

6. The mismatch between responsibilities and resources (such as funding available) is less than the cost of delivery of services, and gaps in infrastructure and the nature of funding programs undermines local solutions and abilities of local authorities.

The authors draw a number of very strong conclusions. Governance arrangements are a threshold cause of policy failure, and policy for remote Australia needs to be separately conceived, framed and 'custom-built' to meet its specific circumstances and needs. The challenge in designing new approaches to governing and administering remote Australia cannot be accommodated in the current governance framework and requires a paradigm shift in policy, one that addresses and changes structurally embedded habits, practices and approaches (Walker et al., 2012, p. 12).

The effectiveness of governance in Northern Australia is identified by other researchers. Governance arrangements are centralised in the state/ territory capitals and Canberra (Babacan et al., 2012; Dale, 2013). For example, Dale (2013) identifies that people in the Kimberley may have a lot more in common with Weipa, but have to go through Perth or Brisbane without any connectivity. He concludes:

by and large, the three jurisdictions tend to manage common issues in isolation. Canberra's relationships with them are also compartmentalised, with high levels of communication fragmentation in and across major Commonwealth ministries and programs (Dale, 2013, p. 10). 
Dale (2013, p. 11) further argues that this leads to a 'high level of frustration both among northern Australian communities and even among the North's elected members'. This is supported by evidence from service providers and communities. For example, an Australian Government evaluation of remote Indigenous service providers found that the pace and volume of recent policy changes caused confusion and frustration largely due to a lack of clear and consistent information from departments. Service providers also noted that current funding arrangements are worse than those of five years ago, with increased red tape, reduced funding and impaired coordination between government departments (Australian Government, 2009, p. 5).

The need for cross-Northern Australia governance arrangements at different levels of government, business and community is being recognised with initiatives such as the establishment of the Northern Australian Ministerial Forum and RDA Boards. These are beginning to strengthen cross-jurisdictional policy debates and involve diverse stakeholders in the policy, planning and implementation processes. While these initiatives are to be applauded, they focus their attention on a limited number of areas, particularly those relating to economic and infrastructure development. As argued by Dale (2013), the vast majority of government-based policymaking, program design and budget development remains in the south. In Queensland and Western Australia, the locus of political decision-making sits in Brisbane and Perth respectively. The representation and participation of the stakeholders in northern Western Australia and Queensland to influence decision-makers is limited. Moreover, the level of interest in Northern Australia by departmental agencies is not strong (Dale, 2013, p. 14). While the NT's capital is located in Northern Australia, it does not have the status of a state and is largely dependent on the federal government located in Canberra, and has to compete for prioritisation with other national agendas.

Ways of addressing governance fragmentation in Northern Australia are beginning to be discussed (Dale, 2013; Babacan et al., 2012; Rouxet al., 2014). For example, a pan-Northern Australia policy architecture is needed, which links into Council of Australian Governments (as a standing item) and WA, the NT, Queensland and Australian cabinet processes and budget cycles (Roux et al., 2014). Roux et al., in the context of economic development, argue that Australian, state and territory governments should seek bilateral agreement about how to best support connectivity in the north by: 
better defining the role of key regional and local players in strategic planning for (and the implementation of) regional economic development. There should be a focus on RDAs, Development Commissions, REDOs, local government and Indigenous organisations and positive approaches to improving the system. (Roux et al., 2014, p. xvi)

While regional bodies such as RDAs have been tasked with regional planning, and numerous consultative bodies exist to mediate complex governmental and regional socioeconomic systems, they lack authority, decision-making power and resources (Pugalis \& Keegan, 2017; Pape et al., 2016). Walker et al. (2012, p. 65) argue for the need for placebased responses and regional innovations and call for the introduction of an authority with comprehensive oversight at regional levels, whereby any jurisdictional overlaps are negotiated.

There is very little collaboration across the human services sectors, although regional bodies exist. For example, the Cairns Social Services Alliance, a network of services in Far North Queensland, has called for policy and human services reform (Babacan, 2011). Diverse Indigenous governance systems characterise Northern Australia, organised around traditional owner groups, land trusts and not-for-profit service agencies. Indigenous leaders in Northern Australia have also been calling for governance reform such as rights-based reforms in the governance for land, community development and welfare work (North Australian Indigenous Land and Sea Management, 2012), and Noel Pearson (2013) has called for welfare reform.

Pointing to disconnect, disengagement and discontent, consultations undertaken by Desert Knowledge Australia revealed what people want: a say in decisions that affect them, equitable and sustainable financial flows, better services and a locally responsive public service, local control and accountability where possible, and inclusion in a greater Australian narrative (Walker et al., 2012, p. 9). This is supported by other researchers who argue that short-term, fragmented, inflexible and annualised government program delivery models simply do not work in Northern Australia (Dale, 2013). Walker et al. (2012, p. 10) provide an important caution not to view governance issues, particularly in remote locations, as 'Aboriginal issues'. They argue that this is a mistake, as many non-Aboriginal people face similar issues. It has been argued that centralisation of power and people, and the strict regulatory and policy measures adopted for funding for welfare services by federal and state governments, have resulted in highly standardised services that have 
problems with responding to diversity of needs and populations (Walker et al., 2012; Cheers, 1992). Walker et al. (2012, p. 18) concluded that 'funding criteria and rules relating to delivery and acquittal are centrally determined and provide little opportunity for local variation and for crossprogram coordination and integration'. In an evaluation by the Office of Evaluation and Audit (Indigenous Programs) of service delivery to remote Indigenous communities, over 58 per cent of respondents thought the Australian Government was underperforming in relation to long-term funding agreements, and over 50 per cent rated as poor or below average the user-friendliness of grant application and reporting arrangements (Australian Government, 2009, p. 41). Conversely, in regard to the factors that mattered the most in having a good relationship with the Australian Government, having reliable and responsive staff was the most important and a good understanding of remote communities by the staff was the second-most important (Australian Government, 2009, p. 42). A quotation from one of the service providers summarises the key issues quite concisely:

The ICC [Indigenous Coordination Centres] should be more hands on and less bureaucratic. It is not possible to make assessments and judgements about community needs based on a visit once or twice a year and for only a couple of hours. They also could be much more proactive in working with communities to identify needs and to follow up with various departments where funding or support could be obtained to meet these needs. (Australian Government, 2009, p. 45)

The importance of integrated and coordinated approaches cannot be overstated. For example, the OECD (2012, p. 10), in a study of 23 regional case studies across Europe, identified that success was based on improvements in horizontal coordination of policies, regional institutional capacities, infrastructure provision and human capital development. Quality of institutions, labour market fragmentation and connectivity were essential elements of prosperous regional development. Successful regional approaches require addressing a range of challenges at the same time, but, as many authors point out, not in a nuanced manner (Cheers, 1992; OECD, 2016).

Addressing governance issues in Northern Australia will require a shift to an approach that focuses on engagement of stakeholders who are most affected. However, who is engaged and the capacity of citizens to participate in the choices that affect them is integral to any conception 
of governance (Dale, 2013; Walker et al., 2012). Building civic capacity for participation is crucial. For example, in an Australian Government evaluation of Indigenous remote service delivery, it was identified that many of the service providers have a limited understanding of the structure and responsibilities of Australian Government departments. There was also confusion about the split of responsibilities between the Australian Government and state/territory governments (Australian Government, 2009 , p. 4). It is argued that local institutions in Northern Australia are being overwhelmed by the changes taking place; many are unsuited to the tasks they confront and, as a consequence, they are unable to create durable and equitable arrangements to manage conflict, deliver services or sponsor entrepreneurial activity (Walker et al., 2012, p. 31). Developing strong communities and institutions is a key to the future of Northern Australia (Babacan, 2013).

Achieving integration and planning in human services will not happen by itself and will require intentional effort and resources. As Keast et al. (2012, p. 5) argue, integration and planning:

is not easy to achieve nor is it an inexpensive undertaking, it requires dedicated consideration, planning, resourcing and adequate funding. In particular, interpersonal relationships are resource and labour intensive with associated (albeit often transparent) transaction costs and must be legitimised as a 'core' element of work and adequately funded. Coordination or linking points are critical in holding the elements of the system together and, when necessary, mobilise them to action.

Integration and coordination requires a shift of mindsets and practice of how policies and programs are designed and implemented. The RAI (2013, p. 76) posits that the challenge for policy is to create an approach that devolves genuine responsibility to people, incentivises their leadership in building a different future and provides the time needed for this seismic shift in approach to occur. The Productivity Commission (2017) states that regional development can take place with locally owned strategic approaches, capitalising on a region's strengths and endowments, investing in people's capabilities and regional connectivity. Northern Australia's diversity implies that generalised policies and programs will not be effective and the 'one-size-fits-all' approach to meeting community needs will not work. For this reason, many advocate place-based approaches (Walker et al., 2012; CSSA, 2014; Dale, 2013) to ensure responsiveness to local imperatives and the ability to tailor to local issues. 


\section{Conclusion and Future Directions}

Northern Australia is diverse, vast and sparsely populated. Most of Northern Australia spans the categories of regional, rural and remote. There is a significant link between geography, demography and social problems. There is considerable evidence that spatial location impacts negatively on wellbeing and increases disadvantage.

This chapter has demonstrated significant disadvantage in Northern Australia in general and severe and persistent Indigenous disadvantage in all major indicators of health and wellbeing in particular. Approaches to social problems is generally patchy and fragmented. A 'one-size-fits-all' approach is known not to work for Northern Australia, given the diversity, governance, social, environmental and economic issues unique to both Northern Australia and rural/remote and very remote communities (CSSA, 2014).

Services are disconnected and wide-ranging systemic failures pose a constant set of barriers to providing adequate support. One step towards improvement may be to fill major data gaps informing planning in governance arrangements, and the coordination and service delivery. There is insufficient evidence about what service models work best, in what locations, for type of services and for which social issue. What has been established is that the people living in regions across Northern Australia want a clear voice in the decisions that affect them, equitable and sustainable funding flows, improved locally based providers and public service, and local control and accountability (Babacan, 2014).

Northern Australia will continue to gain significance for a range of economic, political, social and cultural reasons. However, a renewed focus in Northern Australia is unlikely to succeed if human capital and social issues are not addressed. A number of areas require priority attention.

\section{Responsiveness to Community Need and Adoption of Place-Based Approaches}

The social disadvantage in Northern Australia requires culturally and locally relevant approaches to produce socially just outcomes. Different policy and service sectors work across purposes within regions in a conflicting, disjointed or duplicating manner (Brown \& Bellamy, 2010). The lack of capacity for identifying and planning for significant regional/ 
rural priorities has been demonstrated. The underlying causes included lack of capacity and expertise, inadequate data and evidence base, lack of collaboration, lack of coordination, lack of authority and lack of resources (Productivity Commission, 2017; Eversole, 2017; Pape et al., 2016). The lack of focus on strategic rural/regional planning has flow-on impacts for attracting investments for the region, policymaking and service delivery and design. The capacity of individuals and organisations to effectively participate in civic processes is fundamental to responsive outcomes. Appropriate representation and participation in human service planning, community development and policy processes by those who are affected can result in regional innovation and shift the effort from redistributive and welfare approaches to empowerment and place-based opportunities.

\section{Building an Evidence Base}

There is a clear lack of evidence to guide decision-making in Northern Australia, particularly in human services. There is an urgent need to have appropriate data about the nature of social issues. Disaggregated data needs to be available to inform decision-making processes, particularly about topics such as welfare expenditure, service use and availability and workforce. Additionally, research is needed on a range of issues affecting the human services sector such as effectiveness of service delivery models, workforce issues, and the nature of need in specific locations and impacts of policy. There is a need to build capacity in Northern Australia to undertake social impact assessment, needs analysis and social research to better support human services sector in Northern Australia by the universities.

\section{Integrated Planning, Service Coordination and Relevant Policy Development}

It is clear that centralised funding and policy models have produced variable results across Northern Australia. Walker et al. (2012) have argued that there is dysfunction in governance arrangements. The distance and the lack of presence of state and federal governments in Northern Australia has been noted, bringing with it criticism of lack of knowledge about the realities of Northern Australia in policymaking and the inability to influence key strategies and policies. Regional mechanisms that are devolved can produce integrated and coordinated approaches to service planning in Northern Australia. This means progressing mechanisms for formal, informal and cross-sectoral planning and delivery, driven 
by local stakeholders and local leadership. Moreover, it is critical that such devolved approaches are embedded in policy frameworks so that decision-making is not driven from Canberra, Brisbane, Darwin or Perth for Northern Australia. Effort is required to develop appropriate governance mechanisms at the third-sector level, clearly articulating connectivity, a vision for the sector and strategies to address capacity and social infrastructure constraints. There is a need for a Northern Australia community services umbrella agency or council, rather than the state/ territory-based ones trying to undertake outreach, to be an advocate to address sectoral issues. Taking a cross-Northern Australia approach to address issues has been advocated in the recent past by Dale (2013, p. 21), who argued for 'communities across the north working more effectively as a block towards more joined-up and negotiated governance'. Governance and organisational mechanisms will need to be established to enable the ability to work across different levels of governments that are likely to have different policy agendas and delivery mechanisms. Dale (2013) identifies examples of such cross alliances emerging in Northern Australia in different sectors such as conservation, environmental sustainability and in higher education (particularly research).

\section{Ongoing and Secure Funding Models}

There has been a chronic underinvestment in Northern Australia per capita for health and human service delivery. While the fragmentation in the sector is well known, the service gaps, capacity and resource constraints and priority areas are not well documented at the subregional level. There is a need to develop ongoing funding models that provide preventative, sustainable and outcome-based service delivery, rather than the current ad hoc, competitive and fragmented approaches. Programmatic approaches to funding over a number of years is critical, rather than one-off competitive models. The 'churning' of services and workforce due to poor funding models results in greater long-term inefficiencies and wastage of precious public resources. Best and Myers (2017, p. 7) conclude that there are benefits to funding relationships, which involve:

multi-stakeholder, multi-agency active alliances, where it is possible to identify new and different routes to providing rural health and social care and to engage in networking and outreach activities that moved the focus of provision beyond traditional institutional boundaries into rural communities. 
While government will continue to be the main funder of health and human services, there is a need to diversify the funding base with strategies to enable support from the private sector and philanthropic organisations, which requires incentives to trial different partnership models across sectors.

\section{Sector Capacity-Building and Workforce Development}

It is important to document the nature of workforce and skills issues for the human sector across Northern Australia as there is a critical gap in our knowledge base. There is a need to address workforce loss of skills due to short-term funding in the non-government sector. Regional, coordinated and cohesive efforts are needed to attract and retain employees in Northern Australia, addressing professional, personal and community issues. It is important to develop improved future career progression strategies in the social and community services industry by education, training and professional development initiatives.

While Northern Australia continues to experience strong growth in the planning capacity of its economic and natural resource sectors, the social and human services sectors have not been supported at a strategic level. Building an environment conducive to this requires multidimensional approaches, and neglecting the human services sector will have serious long-term consequences economically, socially and in other ways. Failing to invest in the human services sector will have detrimental impacts on sustainable communities, the development of vibrant economies, opportunities for socioeconomic participation and inclusive cultural and social cohesion. It is critical that local service providers are enabled to find localised solutions. Providing adequate support, enabling cross-sector alliance, supporting capacity-building, enabling mobilisation of external assets/triggers and multi-level governance are key to innovation in, and revitalisation of, Northern Australia.

\section{References}

Alston, M. \& Kent, J. (2004). Coping with a crisis: Human services in times of drought. Rural Society, 14, 214-227. 
Altman, J. \& Russell, S. (2012). Too much 'Dreaming': Evaluations of the Northern Territory National Emergency Response Intervention 2007-2012. Evidence Base, 3. doi.org/10.21307/eb-2012-003

Australian Bureau of Statistics (ABS). (2016). Socio-economic indexes for areas (No. 2033.0.55.001). Canberra, ACT: ABS. Retrieved www.abs.gov.au/ websitedbs/censushome.nsf/home/seifa

Australian Bureau of Statistics (ABS). (2017). Patient experience survey, 20172018 (No. 4839.0). Canberra, ACT: ABS. Retrieved from www.abs.gov.au/ AUSSTATS/abs@.nsf/Lookup/4839.0Main+Features12017-18

Australian Government. (2009). Evaluation of service delivery in remote Indigenous communities. Canberra, ACT: Office of Evaluation and Audit (Indigenous Programs), Commonwealth of Australia.

Australian Government. (2014). Closing the gap. Prime Minister's report 2014. Canberra, ACT: Commonwealth of Australia.

Australian Government. (2015). Our north, our future: White paper on developing Northern Australia. Retrieved from www.industry.gov.au/data-and-publications/ our-north-our-future-white-paper-on-developing-northern-australia

Australian Institute of Health and Welfare (AIHW). (2007). Welfare expenditure Australia 2005-06. Canberra, ACT: AIHW.

Australian Institute of Health and Welfare (AIHW). (2011). Australia's welfare 2011 (Cat. No. AUS 142). Canberra, ACT: AIHW.

Australian Institute of Health and Welfare (AIHW). (2013). Australia's welfare 2013 (Cat. No. AUS 174). Canberra, ACT: AIHW.

Australian Institute of Health and Welfare (AIHW). (2014a). Australia's health 2014 (Australia's Health Series No. 14, Cat. No. AUS 178). Canberra, ACT: AIHW.

Australian Institute of Health and Welfare (AIHW). (2014b). Health expenditure Australia 2011-12: Analysis by sector (Health and Welfare Expenditure Series No. 51, Cat. No. HWE 60). Canberra, ACT: AIHW.

Australian Institute of Health and Welfare (AIHW). (2017a). Australia's welfare 2017 (Cat No. AUS 214). Canberra, ACT: AIHW.

Australian Institute of Health and Welfare (AIHW). (2017b). Health expenditure Australia 2015-16 (Health and Welfare Expenditure Series No. 58, Cat. No. HWE 68). Canberra, ACT: AIHW. 
Australian Institute of Health and Welfare (AIHW). (2017c). Survey of health care: Selected findings for rural and remote Australians (Cat No. PHE220). Canberra, ACT: AIHW.

Babacan, H. (2011). Social and community services in Far North Queensland: Issues facing the sector (unpublished consultation report). Cairns, Qld: James Cook University.

Babacan, H. (2013). Social and community services in Northern Australia (unpublished consultation brief, in partnership with Regional Development Australia Far North Queensland).

Babacan, H. (2014). Human services sector development in Northern Australia. In The Regional Australia Institute (Ed.), Green paper on developing Northern Australia: A joint submission to the Northern Australia Taskforce. Canberra, ACT: RAI.

Babacan, H. (2017). Investing in 'the Social' in Northern Australia. Paper presented at the Developing Northern Australia Conference, 19-20 June, Cairns, Qld.

Babacan, H. \& Babacan, A. (2007). Sustaining human security. The International Journal of Environmental, Cultural, Economic and Social Sustainability, 3(1), $115-122$.

Babacan, H., Dale, A., Andrews, P., Beazley, L., Horstman, M., Campbell, A., ... Miley, A. (2012). Science engagement and tropical Australia: Building a prosperous and sustainable future for the North (Report). Department of Industry, Innovation, Science, Research and Tertiary Education. Retrieved from researchonline.jcu.edu.au/23871/

Baldwin, R., Stephens, M., Sharp, D. \& Kelly, J. (2013). Issues facing age care services in rural and remote Australia. Canberra, ACT: Aged \& Community Services Australia.

Battye, K. (2007). Workforce shortages or dysfunctional service models? Paper presented to the 9th Rural Health Conference, Albury, NSW. Retrieved from ruralhealth.org.au/9thNRHC/9thnrhc.ruralhealth.org.au/keynotes/docs/ presentation/Kristine_Battye.pdf

Best, S. \& Myers, J. (2017). Prudence or speed: Health and social care innovation in rural Wales. Journal of Rural Studies, 1-9. doi.org/10.1016/j.jrurstud. 2017.12.004

Brown, A. J. \& Bellamy, J. A. (2010). In the shadow of Federalism: Dilemmas of institutional design in Australian rural and remote regional governance. Australasian Journal of Regional Studies, 16(2), 151-180. 
Carson, D., Taylor, A. \& Campbell, S. (2009). Demographic trends and likely futures for Australia's tropical rivers. Darwin, NT: Charles Darwin University.

Catholic Social Services Australia (CSSA). (2014). Submission to the Joint Select Committee on Northern Australia. Curtin, Canberra, ACT: CSSA. Retrieved from cssa.org.au/policies-and-submissions/

Cheers, B. (1992). Rural social work and social welfare in the Australian context. Australian Social Work, 45(2), 11-21.

Cheers, B. \& Taylor, J. (2001). Social work in rural and remote Australia. In M. Alston \& J. McKinnon (Eds), Social work: Fields of practice (pp. 206209). Sydney, NSW: Oxford University Press.

Chenoweth, L. \& Stehlik, D. (2001). Building resilient communities: Social work practice and rural Queensland. Australian Social Work, 54(2), 47-54.

Community Services and Health Industry Skills Council. (2014). Environmental scan 2014: Agenda for change. Retrieved from hdl.voced.edu.au/10707/299598

Dale, A. (2013). Governance challenges for Northern Australia. Cairns, Qld: The Cairns Institute, James Cook University.

Davies, A., Tonts, M., Troy, L. \& Pelusey, H. (2009). Australia's rural workforce: An analysis of labour shortages in rural Australia (RIRDC Publication 09/008). Canberra, ACT: Rural Industries Development Corporation.

Defourny, J. \& Nyssens, M. (2013). Social innovation, social economy and social enterprise: What can the European debate tell us? In F. Moulaert, D. MacCallum, M. Abid \& H. Abdelilah (Eds), The international handbook on social innovation (pp. 40-52). Cheltenham, UK; Northampton, MA: Edward Elgar.

Department of Education, Employment and Workplace Relations (DEEWR). (2011). DEEWR annual report 2010-2011. Canberra, ACT: DEEWR.

Department of Families, Housing, Community Services and Indigenous Affairs. (2011). FaHCSIA annual report 2010-11. Canberra, ACT: FaHCSIA.

Department of Industry, Tourism and Trade (2021). NT Key Business Statistics: Labour Market. Retrieved from industry.nt.gov.au/economic-data-andstatistics/business/nt-key-business-statistics/labour-market

Department of Jobs and Small Business. (2018). Industry employment projections 2018 report. Retrieved from cica.org.au/wp-content/uploads/2018-IndustryEmployment-Projections-Report.pdf 
Department of Trade, Business and Innovation. (2017). Northern Territory labour market, 2017. Darwin, NT: Department of Trade, Business and Innovation.

Dollery, B. E., Wallis, J. \& Akimov, A. (2010). One size does not fit all: The special case of remote small local councils in outback Queensland. Local Government Studies, 36(1), 21-42.

Economy Id. (2021). Employment by Industry. Retrieved from economy.id.com. au/fnqroc/employment-by-industry

Eversole, R. (2017). Economies with people in them: Regional futures through the lens of contemporary regional development theory, Australasian. Journal of Regional Studies, 23(3), 305-320.

First Peoples Disability Network. (2013). Making the National Disability Insurance Scheme accessible and responsive to Aboriginal and Torres Strait Islanders: Strategic issues. Sydney, NSW: First Peoples Disability Network (FPDN) Publications.

Fragar, L., Henderson, A., Morton, C. \& Pollock, K. (2007). The mental health of people on Australian farms: The facts. Barton, ACT: Rural Industries Research $\&$ Development Corporation and Australian Centre for Agricultural Health and Safety.

Gopalkrishnan, N. (2007). Neo-Liberalism and infeartainment: What does a state do? In H. Babacan \& N. Gopalkrishnan (Eds), Racisms in the New World Order: Realities of culture, colour and identity (pp. 22-23). Newcastle, England: Cambridge Scholars Publishing.

Gow, K. \& Paton, D. (Eds). (2008). The phoenix of natural disasters: Community resilience. New York, NY: Nova Science Publishers.

Hall, G. \& Scheltens, M. (2005). Beyond the drought: Towards a broader understanding of rural disadvantage. Rural Society, 15(2), 347-358.

Holland, C. (2018). A ten-year review: The Closing the Gap strategy and recommendations for reset. The Close the Gap Campaign Steering Committee. Retrieved from humanrights.gov.au/sites/default/files/document/publication/ CTG\%202018_FINAL-WEB.pdf

House of Representatives Standing Committee on Regional Affairs. (2013). Inquiry into the use of 'Fly-in, Fly-Out' (FIFO) workforce practices in regional Australia. Retrieved from www.aph.gov.au/parliamentary_business/committees/house_ of_representatives_committees?url=ra/fifodido/report.htm 
Judd, F., Jackson, H., Komiti, A., Murray, G., Fraser, C., Grieve, A. \& Gomez, R. (2006). Help-seeking by rural residents for mental health problems: The importance of agrarian values. Australian and New Zealand Journal of Psychiatry, 40, 769-776.

Keast, R., Waterhouse, J., Murphy, G. \& Brown, K. (2012). Pulling it all together: Design considerations for an integrated homelessness service system-Placebased network analysis. Brisbane, Qld: Department of Families, Housing, Community Services and Indigenous Affairs.

Kirmayer, L. J., Sehdev, M., Whitley, R., Dandeneau, F. S. \& Isaac, C. (2009). Community resilience: Models, metaphors and measures. Journal of Aboriginal Health, 5(1), 62-117.

Lamartina, S. \& Zaghini, A. (2008). Increasing public expenditures: Wagner's law in OECD countries (Center for Financial Studies Report No. 2008/13). Retrieved from www.ifk-cfs.de/fileadmin/downloads/publications/wp/08_13.pdf

Limerick, M., Morris, R. \& Sutton, M. (2012). Local government service delivery to remote Indigenous communities. Review of service delivery models and approaches in various jurisdictions. Sydney, NSW: Australian Centre of Excellence for Local Government.

Lonne, B. \& Cheers, B. (2004). Retaining rural social workers: An Australian study. Rural Society, 14(2), 163-177.

Manderson, D. (2008). Not yet: Aboriginal people and the deferral of the rule of law. ARENorthern Australia, 29(30), 219-272.

Massey, L., Jane, A., Lindop, N. \& Christian, E. (2013). Disability auditNE Arnhem Land/NT Gulf-A snapshot of Indigenous Australian disability in the very remote communities of the Groote Eylandt Archipelago (Angurugu, Umbakumba, Milyakburra), Elcho Island (Galiwin'ku), and Ngukurr (including Urapunga). Alyangula, NT: MJD Foundation Limited.

McGregor-Lowndes, M. (2014). The not for profit sector in Australia: Fact sheet (ACPNS Current Issues Information Sheet 2014/4). Brisbane, Qld: Queensland University of Technology. Retrieved from eprints.qut.edu.au/ 753971

Moran, M., Anda, M., Elvin, R., Kennedy, A., Long, S., McFallan, S., ... Young, M. (2009). Desert services that work: Year one research report (Working Paper No. 30). Alice Springs, NT: Desert Knowledge Cooperative Research Centre.

Naldi, L., Nilsson, P., Westlund, H. \& Wixe, S. (2015). What is smart rural development? Journal of Rural Studies, 40, 90-101. 
National Health Priority Areas. (2014). Healthy communities: Potentially preventable hospitalisations in 2013-14. Sydney, NSW: Commonwealth Government.

NEF Consulting. (2010). Catalysts for community action and investment: A social return on investment analysis of community development work based on a common outcomes framework. London, England: Community Development Foundation.

North Australian Indigenous Land and Sea Management Alliance. (2012). Towards resilient communities through reliable prosperity. North Australian Indigenous Experts Forum on Sustainable Economic Development (NKS 013/2012). Retrieved from web.archive.org/web/20150330172117/http://nailsma.org.au/ sites/default/files/publications/Towards-resilient-communities-KS013-web.pdf

Northern Queensland Primary Health Network. (2017). Health needs assessment update 2017-2018. Cairns, Qld: NQPHN.

Organisation for Economic Co-operation and Development (OECD). (2012). Promoting growth in all regions. Retrieved from www.oecd.org/site/govrdpc/ 50138839.pdf

Organisation for Economic Co-operation and Development (OECD). (2016). OECD regional outlook 2016: Productive regions for inclusive societies. Retrieved from doi.org/10.1787/9789264260245-en

Organisation for Economic Co-operation and Development (OECD). (2018). Social expenditure data. Retrieved from stats.oecd.org/Index.aspx?DataSet Code=SOCX_AGG

Pape, M., Fairbrother, P. \& Snell, D. (2016). Beyond the state: Shaping governance and development policy in an Australian region. Regional Studies, 50(5), 909-921.

Pearson, N. (2013, 15-16 June). Failures can't be pinned on Aborigines. The Weekend Australian, p. 19.

Productivity Commission. (2017). Transitioning regional economies, study report. Canberra, ACT: Commonwealth of Australia.

Public Health Information Development Unit. (2014). Atlas of Northern Australia. Adelaide, SA: PHIDU. Retrieved from www.atlasesaustralia.com. au/pmc/atlas.html

Pugalis, L. \& Keegan, D. (2017). The regional economic development paradox: Attempting policy order in the face of societal complexity. Australasian Journal of Regional Studies, 23(1), 68-94. 
Regional Australia Institute (RAI). (2013). Rethinking the future of Northern Australia's regions. Canberra, ACT: RAI.

Regional Australia Institute (RAI). (2015). The future of regional Australia: Change on our terms. Canberra, ACT: RAI.

Richter, D. R. (2017). Rural social enterprises as embedded intermediaries: The innovative power of connecting rural communities with supra-regional networks. Journal of Rural Studies, 1-9. doi.org/10.1016/j.jrurstud.2017. 12.005

Roufeil, L. \& Battye, K. (2008). Effective regional, rural and remote family and relationships service delivery (AFRC Briefing No. 10). Australian Institute of Family Studies. Retrieved from aifs.gov.au/cfca/publications/effectiveregional-rural-and-remote-family-and-relationship

Roux, A., Faubel, M. \& McCauchie, D. (2014). Northern development: Creating the future Australia. Report of the ADC Forum, Northern Development Summit. Melbourne, Vic.: ADC Forum.

Saunders, P. \& Wong, M. (2014). Locational differences in material deprivation and social exclusion in Australia. The Australasian Journal of Regional Studies, 20(1), 131-158.

Social Ventures Australia and the Centre for Social Impact. (2020). Taken for granted? Charities' role in our economic recovery. Social Ventures Australia. Retrieved from mk0socialventuraff85.kinstacdn.com/assets/200804_Takenfor-granted-Charities-role-economic-recovery_CSI-SVA-lg.pdf

Steiner, A. \& Teasdale, S. (2017). Unlocking the potential of rural social enterprise. Journal of Rural Studies, 1-11. doi.org/10.1016/j.jrurstud.2017.12.021

Stephens, A., Cullen, J., Massey, L. \& Bohanna, I. (2014). Will the National Disability Insurance Scheme improve the lives of those most in need? Effective service delivery for people with acquired brain injury and other disabilities in remote Aboriginal and Torres Strait Islander communities. Australian Journal of Public Administration, 73(2), 260-270.

Stoeckl, N. (2010). Bridging the asymmetric divide: Background to, and strategies for bridging the divide between Indigenous and Non-Indigenous economies in Northern Australia. In R. Gerritsen (Ed.), North Australian political economy: Issues and agendas (pp. 106-129). Darwin, NT: CDU Press.

Trinidad, M. (2001). Centacare in the Northern Territory. Australian Social Work, 54(1), 10-13. 
United Nations Economic and Social Commission for Asia Pacific. (2013). AsiaPacific trade and investment report 2013: Turning the tide: Towards inclusive trade and development. Retrieved from www.unescap.org/publications/asia-pacifictrade-and-investment-report-2013-turning-tide-towards-inclusive-trade-and

van Opstal, D. (2007). The resilient economy: Integrating competitiveness and security. Washington, DC: Council on Competitiveness. Retrieved from www.compete. org/storage/images/uploads/File/PDF\%20Files/Transform_The_Resilient_ Economy_FINorthern AustraliaL_pdf.pdf

Wakerman, J., Humphreys, J. S., Wells, R., Kuipers, P., Entwistle, P. \& Jones, J. (2008). Primary health care delivery models in rural and remote Australia: A systematic review. Alice Springs, NT: Centre for Remote Health.

Walker, B., Porter, D. \& Marsh, I. (2012). Fixing the hole in Australia's heartland: How government needs to work in remote Australia. Alice Springs, NT: Desert Knowledge Australia.

Wendt, S. \& Hornosty, J. (2010). Understanding contexts of family violence in rural, farming communities: Implications for rural women's health. Rural Society, 20(1), 51-63.

Winterton, R. \& Warburton, J. (2011). Does place matter? Reviewing the experience of disadvantage of older people in rural Australia. Rural Society, 20(2), 187-197. 
This text is taken from Leading from the North: Rethinking Northern Australia Development, edited by Ruth Wallace, Sharon Harwood, Rolf Gerritsen, Bruce Prideaux, Tom Brewer, Linda Rosenman and Allan Dale, published 2021 by ANU Press, The Australian National University, Canberra, Australia.

doi.org/10.22459/LN.2021.03 